
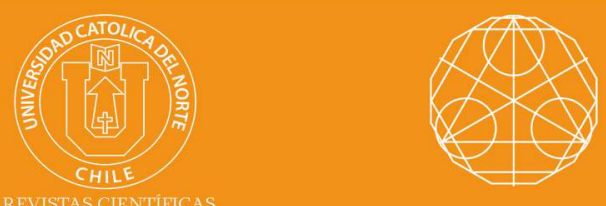

\title{
Near $\omega$-continuous multifunctions on bitopological spaces
}

E. Rosas* (iD) orcid.org/0000-0001-8123-9344

C. Carpintero** (iD) orcid.org/0000-0003-3831-952X

N. Rajesh ${ }^{* * *}$ (iD) orcid.org/0000-0003-0921-6054

S. Shanti*** id orcid.org/0000-0002-6824-033X

*Universidad de la Costa, Dept. de Cs. Naturales y Exactas, Barranquilla, Colombia.

\ ennisrafael@gmail.com

**Universidad de Oriente, Dept. de Matemáticas, Cumaná, Venezuela.

$\checkmark$ carpintero.carlos@gmail.com

${ }^{* * *}$ Rajah Serfoji Govt. College, Dept. of Mathematics Thanjavur, TN, India.

n nrajesh_topology@yahoo.co.in

${ }^{* * * *}$ Arignar Anna Govt. Arts College, Dept. of Mathematics, Namakkal, TB, India.

shanthiwini2005@yahoo.co.in

Received: May 2018 | Accepted: November 2018

\section{Abstract:}

In this paper, we introduce and study basic characterizations, several properties of upper (lower) nearly $(i, j)-\omega$-continuous multifunctions on bitopological space.

Keywords: (i, j)-regular open set; $\omega$-open sets; Upper nearly $(i, j)-\omega$-continuous.

MSC (2010): 54C10, 54C08, 54C05.

\section{Cite this article as (IEEE citation style)}

E, Rosas, C. Carpintero, N. Rajesh and S. Shanti, "Near $\omega$-continuous multifunctions on bitopological spaces", Proyecciones (Antofagasta, On line), vol. 38, no. 4, pp. 691-698, Oct. 2019, doi: 10.22199/issn.0717-6279-2019-04-0044. [Accessed dd-mm-yyyy].

Article copyright: (C) 2019 Ennis Rosas, Carlos Carpintero, Neelamegarajan Rajesh and S. Shanti. This is an open access article distributed under the terms of the Creative Commons Licence, which permits unrestricted use and distribution provided the original author and source are credited. 


\section{Introduction}

It is well known that various types of functions play a significant role in the theory of classical point set topology. A great number of papers dealing with such functions have appeared, and a good number of them have been extended to the setting of multifunctions. This shows that both, functions and multifunctions are important tools for studying other properties of spaces and for constructing new spaces from previously existing ones. Generalized open sets play an important role in General Topology and they are now the research topics of many topologists worldwide. Indeed a significant theme in General Topology and Real analysis concerns the introduction of various modified forms of continuity, separation axioms etc. by utilizing generalized open sets. A generalization of closed sets, the notion of $\omega$-closed sets has been introduced and studied by Hdeib [8]. Several characterizations and properties of $\omega$-closed sets has been provided in $[2,4,5,6,8,9]$. In this paper, we introduce and study upper (lower) nearly $(i, j)$ - $\omega$-continuous multifunctions on bitopological space.

\section{Preliminaries}

Throughout this paper, $\left(X, \tau_{1}, \tau_{2}\right)$ and $\left(Y, \sigma_{1}, \sigma_{2}\right)$ denote the bitopological spaces in which no separation axioms are assumed unless explicitly stated. Bitopological spaces and its different properties have been investigated by Triparthy and Sarma ([11], [12], [14]), Sarma and Triparthy [15], Tripathy and Acharjee [13], Acharjee and Tripathy [1], Tripathy and Debnath [16], and others. For a subset $A$ of $(X, \tau), i C l(A)$ (respectively $i \operatorname{Int}(A))$ denote the closure of $A$ with respect to $\tau_{i}$ (respectively the interior of $A$ with respect to $\tau_{i}$ ). A point $x \in X$ is called a condensation point of $A$ if for each $U \in \tau$ with $x \in U$, the set $U \cap A$ is uncountable. The set $A$ is said to be $\omega$-closed [8] if it contains all its condensation points. The complement of an $\omega$-closed set is said to be an $\omega$-open set. It is well known that a subset $W$ of a space $(X, \tau)$ is $\omega$-open if and only if for each $x \in W$, there exists $U \in \tau$ such that $x \in U$ and $U \backslash W$ is countable. The family of all $\omega$-open subsets of a topological space $(X, \tau)$ forms a topology on $X$ finer than $\tau$. The intersection of all $\omega$-closed sets containing $A$ is called the $\omega$-closure[8] of $A$ and is denoted by $\omega C l(A)$. For each $x \in X$, the family of all $\omega$-open sets containing $x$ is denoted by $\omega O(X, x)$. The family of all $\omega$-open sets of $X$ is denoted by $\omega O(X)$. A Multifunction $F: X \rightarrow Y$ from a topological space $X$ to a topological space $Y$ is a point to set correspondence and is assumed that 
$F(x) \neq \emptyset$ for all $x \in X$. We denote the upper and lower inverse of a subset $V$ of $Y$ by $F^{+}(V)$ and $F^{-}(V)$ (respectively; $F^{+}(V)=\{x \in X: F(x) \subseteq V\}$ and $F^{-}(V)=\{x \in X: F(x) \cap V \neq \emptyset\}$.

\section{Upper (lower) nearly $(i, j)-\omega$-continuous multifunctions}

Definition 3.1. [10] $A$ subset $A$ of a bitopological space $\left(X, \tau_{1}, \tau_{2}\right)$ is said to be $(i, j)$-regular open if $A=i \operatorname{Int}(j C l(A))$. The complement of an $(i, j)$ regular open set is called $(i, j)$-regular closed set.

Definition 3.2. A subset $A$ of a bitopological space $\left(X, \tau_{1}, \tau_{2}\right)$ is said to be $(i, j)$ - $N$-closed [10] if every cover of $A$ by $(i, j)$-regular open sets of $X$ has a finite subcover.

Definition 3.3. A multifunction $F:\left(X, \tau_{1}, \tau_{2}\right) \rightarrow\left(Y, \sigma_{1}, \sigma_{2}\right)$ is said to be:

1. upper nearly $(i, j)$ - $\omega$-continuous at a point $x \in X$ if for each $\sigma_{i}$-open set $V$ containing $F(x)$ and having $(i, j)$-N-closed complement, there exists a $\tau_{i}$-w-open set $U$ containing $x$ such that $U \subset F^{+}(V)$.

2. lower nearly $(i, j)$ - $\omega$-continuous at a point $x \in X$ if for each $\sigma_{i}$-open set $V$ of $Y$ meeting $F(x)$ and having $(i, j)$ - $N$-closed complement, there exists a $\tau_{i}$-w-open set $U$ of $X$ containing $x$ such that $F(u) \cap V \neq \emptyset$ for each $u \in U$.

3. $(i, j)$-upper (resp. $(i, j)$-lower) nearly $\omega$-continuous on $X$ if it has this property at every point of $X$.

Example 3.4. Consider the set $X=Y=\{a, b, c, d\}$ with topologies $\tau_{1}=$ $\sigma_{1}=\{\emptyset, X,\{a\},\{b, c\},\{a, b, c\}\}$ and $\tau_{2}=\sigma_{2}=\{\emptyset, X,\{a\},\{a, b\},\{a, b, c\}\}$. Define the multifunction $F:\left(X, \tau_{1}, \tau_{2}\right) \rightarrow\left(Y, \sigma_{1}, \sigma_{2}\right)$ as follows: $F(a)=$ $\{c\}, F(b)=\{a, b\}, F(c)=\{d\}$ and $F(d)=\{a, b\}$. It is easy to see that the set $\{b, c\}$ is $(i, j)$-regular open and the multifunction $F$ is $(i, j)$-upper (resp. $(i, j)$-lower) nearly $\omega$-continuous on $X$.

Theorem 3.5. For a multifunction $F:\left(X, \tau_{1}, \tau_{2}\right) \rightarrow\left(Y, \sigma_{1}, \sigma_{2}\right)$, the following statements are equivalent:

1. $F$ is upper nearly $(i, j)$ - $\omega$-continuous.

2. $F^{+}(V)$ is $\tau_{i}$ - $\omega$-open for each $\sigma_{i}$-open set $V$ of $Y$ having $(i, j)$ - $N$-closed complement. 
3. $F^{-}(K)$ is $\tau_{i}-\omega$-closed for every $(i, j)$-N-closed and $\sigma_{i}$-closed set $K$ of $Y$.

4. $i \omega C l\left(F^{-}(B)\right) \subset F^{-}(i C l(B))$ for every subset $B$ of $Y$ having $(i, j)-N$ closed $\sigma_{i}$-closure.

5. $F^{+}(i \operatorname{Int}(B)) \subset i \omega \operatorname{Int}\left(F^{+}(B)\right)$ for every subset $B$ of $Y$ such that $Y \backslash i \operatorname{Int}(B)$ is $(i, j)-N$-closed.

Proof. $\quad(1) \Rightarrow(2)$ : Let $x \in F^{+}(V)$ and $V$ be a $\sigma_{i}$-open set of $Y$ having $(i, j)$ - $N$-closed complement. From $(1)$, there exists a $\tau_{i}$ - $\omega$-open set $U_{x}$ containing $x$ such that $U_{x} \subset F^{+}(V)$. It follows that

$F^{+}(V)=\underset{x \in F^{+}(V)}{\cup} U_{x}$. Since arbitrary union of $\tau_{i}$ - $\omega$-open sets is $\tau_{i}$ - $\omega$-open, $F^{+}(V)$ is $\tau_{i}$ - $\omega$-open in $\left(X, \tau_{1}, \tau_{2}\right)$.

$(2) \Rightarrow(3)$ : Let $K$ be any $(i, j)$-N-closed and $\sigma_{i}$-closed set of $Y$. Then by (2), $F^{+}(Y \backslash K)=X \backslash F^{-}(K)$ is an $\tau_{i}$ - $\omega$-open set. Then it is obtained that $F^{-}(K)$ is an $\tau_{i}$ - $\omega$-closed set.

$(3) \Rightarrow(4)$ : Let $B$ be any subset of $Y$ having $(i, j)-N$-closed $\sigma_{i}$-closure. By (3), We have $F^{-}(B) \subset F^{-}(i C l(B))=i \omega C l\left(F^{-}(i C l(B))\right)$. Hence $i \omega C l\left(F^{-}(B)\right) \subset$ $i \omega C l\left(F^{-}(i C l(B))\right)=F^{-}(i C l(B))$.

$(4) \Rightarrow(5)$ : Let $B$ be a subset of $Y$ such that $Y \backslash i \operatorname{Int}(B)$ is $(i, j)-N$-closed. Then by (4), we have $X \backslash i \omega \operatorname{Int}\left(F^{+}(B)\right)=i \omega C l\left(X \backslash F^{+}(B)\right)=i \omega C l\left(F^{-}(Y \backslash B)\right) \subset$ $F^{-}(i C l(Y \backslash B)) \subset X \backslash F^{+}(i \operatorname{Int}(B))$. Therefore, we get $F^{+}(i \operatorname{Int}(B)) \subset$ $i \omega \operatorname{Int}\left(F^{+}(B)\right)$.

$(5) \Rightarrow(1)$ : Let $x \in X$ and $V$ be any $\sigma_{i}$-open set of $Y$ containing $F(x)$ and having $(i, j)$-N-closed complement. Then by (5). $x \in F^{+}(V)=$ $F^{+}(i \operatorname{Int}(V)) \subset i \omega \operatorname{Int}\left(F^{+}(V)\right)$. There exists a $\tau_{i}$ - $\omega$-open set $U$ containing $x$ such that $U \subset F^{+}(V)$; and hence $F(U) \subset V$. This shows that $F$ is upper nearly $(i, j)$ - $\omega$-continuous.

Theorem 3.6. For a multifunction $F:\left(X, \tau_{1}, \tau_{2}\right) \rightarrow\left(Y, \sigma_{1}, \sigma_{2}\right)$, the following statements are equivalent:

1. $F$ is lower nearly $(i, j)-\omega$-continuous.

2. $F^{-}(V)$ is $\tau_{i}$ - $\omega$-open for each $\sigma_{i}$-open set $V$ of $Y$ having $(i, j)-N$-closed complement.

3. $F^{+}(K)$ is $\tau_{i}$ - $\omega$-closed for every $(i, j)-N$-closed and $\sigma_{i}$-closed set $K$ of $Y$. 
4. $i \omega C l\left(F^{+}(B)\right) \subset F^{+}(i C l(B))$ for every subset $B$ of $Y$ having $(i, j)-N$ closed $\sigma_{i}$-closure.

5. $F^{-}(i \operatorname{Int}(B)) \subset i \omega \operatorname{Int}\left(F^{-}(B)\right)$ for every subset $B$ of $Y$ such that $Y \backslash i \operatorname{Int}(B)$ is $(i, j)$-N-closed.

Proof. The proof is similar to that of Theorem 3.5

Corollary 3.7. A multifunction $F:\left(X, \tau_{1}, \tau_{2}\right) \rightarrow\left(Y, \sigma_{1}, \sigma_{2}\right)$ is upper nearly $(i, j)-\omega$-continuous (resp. lower nearly $(i, j)-\omega$-continuous) if $F^{-}(K)$ is $\tau_{i}$ - $\omega$-closed (resp. $F^{+}(K)$ is $\tau_{i}$ - $\omega$-closed) for every $(i, j)$ - $N$-closed set $K$ of $Y$.

Proof. Let $G$ be any $\sigma_{i}$-open set of $Y$ having $(i, j)$ - $N$-closed complement. Then $Y \backslash G$ is an $(i, j)-N$-closed. By the hypothesis, $X \backslash F^{+}(G)=$ $F^{-}(Y \backslash G)=i \omega \operatorname{Int}\left(F^{-}(Y \backslash G)\right)=i \omega C l\left(X \backslash F^{+}(G)\right)=X \backslash i \omega \operatorname{Int}\left(F^{+}(G)\right)$ and hence, $F^{+}(G)=i \omega \operatorname{Int}\left(F^{+}(G)\right)$. It follows from Theorem 3.5 that $F$ is upper nearly $(i, j)$ - $\omega$-continuous. The proof of lower nearly $(i, j)-\omega$ continuity can be established similarly.

For a multifunction $F:\left(X, \tau_{1}, \tau_{2}\right) \rightarrow\left(Y, \sigma_{1}, \sigma_{2}\right)$, we define $D_{n(i, j) \omega}^{+}(F)$ and $D_{n(i, j) \omega}^{-}(F)$ as follows:

$D_{n(i, j) \omega}^{+}(F)=\{x \in X: F$ is not upper nearly $(i, j)$ - $\omega$-continuous at $x\}$. $D_{n(i, j) \omega}^{-}(F)=\{x \in X: F$ is not lower nearly $(i, j)-\omega$-continuous at $x\}$.

Theorem 3.8. For a multifunction $F:\left(X, \tau_{1}, \tau_{2}\right) \rightarrow\left(Y, \sigma_{1}, \sigma_{2}\right)$, the following properties hold:

$$
\begin{aligned}
D_{n(i, j) \omega}^{+} & =\underset{G \in \sigma N C}{\cup}\left\{F^{+}(G) \backslash i \omega \operatorname{Int}\left(F^{+}(G)\right)\right\} \\
& =\bigcup_{B \in i N C}\left\{F^{+}(i \operatorname{Int}(B)) \backslash i \omega \operatorname{Int}\left(F^{+}(B)\right)\right\} \\
& =\bigcup_{B \in N C}\left\{i \omega C l\left(F^{-}(B)\right) \backslash F^{-}(i C l(B))\right\} \\
& =\bigcup_{H \in \mathcal{F}}\left\{i \omega C l\left(F^{-}(H)\right) \backslash F^{-}(H)\right\} .
\end{aligned}
$$

Where

$\sigma N C$ is the family of all $\sigma_{i}$-open sets of $Y$ having $(i, j)-N$-closed complement,

$i N C$ is the family of all subsets $B$ of $Y$ such that $Y \backslash i \operatorname{Int}(B)$ is $(i, j)-N$ closed,

$N C$ is the family of all subsets $B$ of $Y$ having the $(i, j)$ - $N$-closed $\sigma_{i}$-closure, $\mathcal{F}$ is the family of all $\sigma_{i}$-closed and $(i, j)-N$-closed sets of $\left(Y, \sigma_{1}, \sigma_{2}\right)$. 
Proof. We shall establish only the first equality and the last equality since the proofs of other are similar to the first. Let $x \in D_{n(i, j) \omega}^{+}(F)$. Then there exists an $\sigma_{i}$-open set $V$ of $Y$ containing $F(x)$ and having $(i, j)-N$ closed complement such that $x \in i \omega \operatorname{Int}\left(F^{+}(V)\right)$. Therefore, we have $x \in$ $F^{+}(V) \backslash i \omega \operatorname{Int}\left(F^{+}(V)\right) \subset \underset{G \in \sigma N C}{\cup}\left\{F^{+}(G) \backslash i \omega \operatorname{Int}\left(F^{+}(G)\right)\right\}$. Conversely, let $x \in \underset{G \in \sigma N C}{\cup}\left\{F^{+}(G) \backslash i \omega \operatorname{Int}\left(F^{+}(G)\right)\right\}$. Then there exists a $\sigma_{i}$-open set $V$ of $Y$ having $(i, j)$-N-closed complement such that $x \in F^{+}(V) \backslash i \omega \operatorname{Int}\left(F^{+}(V)\right)$. Hence $x \in D_{n(i, j)}^{+}(F)$. We prove the last equality. $\underset{H \in \mathcal{F}}{\cup}\left\{i \omega C l\left(F^{-}(H)\right) \backslash F^{-}(H)\right\} \subset$ $\underset{B \in N C}{\cup}\left\{i \omega C l\left(F^{-}(B)\right) \backslash F^{-}(i C l(B))\right\}=D_{n(i, j) \omega}^{+}(F)$. Conversely, we have $D_{n(i, j) \omega}^{+}(F)=$

$\underset{B \in N C}{\bigcup}\left\{i \omega C l\left(F^{-}(B)\right) \backslash F^{-}(i C l(B))\right\} \subset \underset{H \in \mathcal{F}}{\cup}\left\{i \omega C l\left(F^{-}(H)\right) \backslash F^{-}(H)\right\}$

Theorem 3.9. For a multifunction $F:\left(X, \tau_{1}, \tau_{2}\right) \rightarrow\left(Y, \sigma_{1}, \sigma_{2}\right)$, the following properties hold:

$$
\begin{aligned}
D_{n(i, j) \omega}^{-} & =\bigcup_{G \in \sigma N C}\left\{F^{-}(G) \backslash i \omega \operatorname{Int}\left(F^{-}(G)\right)\right\} \\
& =\bigcup_{B \in i N C}\left\{F^{-}(i \operatorname{Int}(B)) \backslash i \omega \operatorname{Int}\left(F^{-}(B)\right)\right\} \\
& =\bigcup_{B \in N C}\left\{i \omega C l\left(F^{+}(B)\right) \backslash F^{+}(i C l(B))\right\} \\
& =\bigcup_{H \in \mathcal{F}}\left\{i \omega C l\left(F^{+}(H)\right) \backslash F^{+}(H)\right\} .
\end{aligned}
$$

Proof. The proof is similar to that of Theorem 3.8

Definition 3.10. Let $(X, \tau)$ be a topological space and $A$ a subset of $X$. The $\omega$-frontier of $A, \omega-F r(A)$, is defined by $\omega-F r(A)=\omega C l(A) \cap$ $\omega C l(X \backslash A)=\omega C l(A) \backslash \omega \operatorname{Int}(A)$.

Theorem 3.11. For a multifunction $F:\left(X, \tau_{1}, \tau_{2}\right) \rightarrow\left(Y, \sigma_{1}, \sigma_{2}\right), D_{n(i, j) \omega}^{+}(F)$ (resp. $\left.D_{n(i, j) \omega}^{-}(F)\right)$ is identical with the union of $\omega$-frontiers of the $(i, j)$ upper (resp. $(i, j)$-lower) inverse images of $\sigma_{i}$-open sets containing (resp. meeting) $F(x)$ and having $(i, j)$ - $N$-closed complement.

Proof. We shall established the first case since the proof of the second can be established similar.

Let $x \in D_{n(i, j) \omega}^{+}(F)$. Then, there exists a $\sigma_{i}$-open set $V$ of $Y$ containing $F(x)$ and having $(i, j)$-N-closed complement such that $U \cap\left(X \backslash F^{+}(V)\right) \neq \emptyset$ for every $(i, j)$-open set $U$ containing $x$. Then we have $x \in i \omega C l\left(X \backslash F^{+}(V)\right)$. 
On the other hand, since $x \in F^{+}(V) \subset i \omega C l\left(F^{+}(V)\right)$ and hence $x \in i \omega$ $\operatorname{Fr}\left(F^{+}(V)\right)$. Conversely, suppose that $F$ is upper nearly $(i, j)$ - $\omega$-continuous at $x \in X$. Then for any $\sigma_{i}$-open set $V$ of $Y$ containing $F(x)$ and having $(i, j)$-N-closed complement, there exists $U \in \tau_{i}-\omega O(X)$ containing $x$ such that $F(U) \subset V$; hence $x \in U \subset F^{+}(V)$. Therefore, $x \in U \subset$ $i \omega \operatorname{Int}\left(F^{+}(V)\right)$. This contradicts to the fact that $x \in i \omega-F r\left(F^{+}(V)\right)$.

\section{References}

[1] S. Acharjee and B. Tripathy, "p-J generator and p1-J-generator in bitopology," Boletim da Sociedade Paranaense de Matemática, vol. 36, no. 2, pp. 17-31, Apr. 2018, doi: 10.5269/bspm.v36i2.29377.

[2] K. Al-Zoubi and B. Al-Nashef, "The topology of $\omega$-open subsets", Al-Manarah, vol. 9, no. 2, pp. 169-179, 2003.

[3] K. Al-Zoubi, "On generalized $\omega$-closed sets," International journal of mathematics and mathematical sciences, vol. 2005, no. 13, pp. 2011-2021, 2005, doi: 10.1155/IJMMS.2005.2011.

[4] A. Al-Omari and M. Noorani, "Contra- $\omega$-continuous and almost contra- $\omega$-continuous," International journal of mathematics and mathematical sciences, vol. 2007, 40469, 2007, doi:10.1155/2007/40469.

[5] A. Al-Omari, T. Noiri, and M. .Noorani, "Weak and strong forms of $\omega$-continuous functions," International journal of mathematics and mathematical sciences, vol. 2009, 174042, 2009, doi:10.1155/2009/174042.

[6] C. Carpintero, J. Pacheco, N. Rajesh, E. Rosas, and S. Saranyasri, "Properties of nearly $\omega$-continuous multifunctions," Acta universitatis sapientiae, mathematica, vol. 9, no. 1, pp. 13-25, Aug. 2017,. doi: 10.1515/ausm-2017-0002.

[7] E. Ekici, S. Jafari and S. Moshokoa, "On a weak form of $\omega$-continuity", Annals of the university of Craiova, mathematics. computer. sciences series, vol. 37, no. 2, pp. 38-46, 2010. [On line]. Available: https://bit.ly/30ZzYjM

[8] H. Hdeib, " $\omega$-closed mappings", Revista colombiana de matemáticas, vol. 16, no. 1-2, pp. 65-78, Oct. 1982.[On line]. Available: https://bit.ly/20rpGqh

[9] H.. Hdeib, " $\omega$-continuous functions", Dirasat, vol.16, no.2, pp. 136-142, 1989.

[10] A. Richlewicz, "On almost nearly continuity with reference to multifunctions in bitopological spaces", Novi Sad journal of mathematics, vol.38, no. 2, 2008, pp. 5-14, 2008. [On line]. Available: https://bit.ly/2pWW6yE 
[11] B. Tripathy and D. Sarma, "On b-locally open sets in bitopological spaces", Kyungpook mathematical. journal, vol. 51, no. 4, pp. 429433, 2011. [On line]. Available: https://bit.ly/2ogh5fu

[12] B. Tripathy and D. Sarma, "On weakly b-continuous functions in bitopological spaces", Acta scientiarum technology, vol. 35, no.3, pp. 521-525, Feb. 2013, doi: 10.4025/actascitechnol.v35i3.15612

[13] B. Tripathy and S. Acharjee, "On $(\gamma, \delta)$-Bitopological semi-closed set via topological ideal", Proyecciones (Antofagasta, On line), vol. 33, no. 3, pp. 245-257, Mar. 2017, doi: 10.4067/S0716-09172014000300002

[14] B. Tripathy and D. Sarma, "Generalized b-closed sets in ideal bitopological spaces", Proyecciones (Antofagasta, On line), vol. 33, no. 3, pp. 315-324, Mar. 2017, doi: 10.4067/S0716-09172014000300006

[15] D. Sarma and B. Tripathy, "Pairwise generalized b-Ro spaces in bitopological spaces.", Proyecciones (Antofagasta, On line), vol. 36, no. 4, pp. 589-600, Jan. 2018, doi: 10.4067/S0716-09172017000400589

[16] B. Tripathy and S. Debnath, "Fuzzy m-structures, m-open multifunctions and bitopological spaces", Boletim da sociedade paranaensede matemática, vol. 37, no. 4,pp. 119-128, 2019, doi: 10.5269/bspm.v37i4.35152 